Original Research Paper

\title{
SSR Analysis of the Chloroplast and Mitochondrial Genomes of Cultivar Lines and Wild Types of the Sunflower (Helianthus L.)
}

\author{
${ }^{1}$ Vladimir Arturovich Khachumov, ${ }^{1}$ Alexander Vyacheslavovich Usatov, ${ }^{1}$ Kirill Vitalievich Azarin, \\ ${ }^{1}$ Nikolay Victorovich Markin, ${ }^{2}$ Vera Alekseevna Gavrilova, ${ }^{3}$ Oleg Fedorovich Gorbachenko and ${ }^{3}$ Fedor \\ Ivanovich Gorbachenko \\ ${ }^{1}$ Department of Genetics, Southern Federal University, Rostov-on-Don, Russia \\ ${ }^{2}$ Department of Genetic Resources, N. I. Vavilov Institute of Plant Genetic Resources, Saint Petersburg, Russia \\ ${ }^{3}$ Donskaya Experimental Station of VNIIMK, Pustovoit All-Russian Research Institute of Oil Crops, Pos. Oporny, Rostov \\ Region, Russia
}

Article history

Received: 24-01-2020

Revised: 09-02-2020

Accepted: 19-02-2020

Corresponding Author:

Khachumov Vladimir

Arturovich

Department of Genetics,

Southern Federal University,

Rostov-on-Don, Russia

Email: VladimirKhachumov@yandex.ru

\section{Introduction}

Sunflower is a valuable crop cultivated all over the world. To intensify the crops selection, carry out investigation of DNA polymorphism inbred lines and wild sources plants (Usatov et al., 2014; Kaur et al., 2019). Modern research methods allow the most effective study of the genetic diversity of organisms and use it in population and breeding studies (Song et al., 2018). Molecular markers are among the pre-requisites to accelerate the crop breeding program through genomics assisted breeding (Bohra et al., 2017). Furthermore, plant breeding still rely heavily on the inner genetic resources, which are essential to accurately identify genotypes and to delineate the various genetic relationships between available accessions in germplasm collections. These resources can be utilized effectively to preserve and develop the species and to enhance its applications (Mornkham et al., 2016).

SSR markers are widespread tool in crop selection and plant systematics area (Zong et al., 2015). Plastids and mitochondria are usually uniparentally inherited, typically maternally. As genomes of chloroplasts and mitochondria do not undergo sexual recombination are a good tool for studying accumulated differences at them. The contribution of the cytoplasm to the adaptive potential of plants to environmental factors has a greater impact than previously thought (Mashkina et al., 2010; Usatov et al., 2016; Sobanski et al., 2019). Generally, for cultivar lines characterized lower level of polymorphism of the chloroplast genome relative wild type forms (Wills et al., 2005; Singh et al., 2015).

The objective of the current research was to estimate the genetic diversity and Polymorphic Information Contents (PIC) among in the Sunflowers (Helianthus L.) species using PCR-based SSR markers.

\section{Materials and Methods}

\section{Plant Materials}

The study was carried out on the sunflower (Helianthus L.) from the collection of the All-Russian plant genetic resources named N.I. Vavilov. The samples was represented by $H$. decapetalus, $H$. divaricatus, $H$. grosseserratus, $H$. hirsutus, $H$. microcephalus, $H$. occidentalis, $H$. rigidus, $H$. salicifolius, $H$. strumosus, $H$. tuberosus, $H$. argophyllus, $H$. bolanderi, $H$. debilis, $H$. 
neglectus, H. praecox, H. petiolaris, H. annuus (15 different numbers of introductions) and 16 cultivar lines.

\section{DNA Isolation}

The total DNA was isolated from the first pair of true leaves of sunflower seedlings according to Boom et al. (1990) with our modification.

\section{DNA Amplification}

SSR analysis was carried out using 18 primer pairs, the forward of which (F) was labeled 5(6)carboxyfluorescein (FAM) by the 5'-terminal. Design of primers based on the reference plastid genome of the HA383 line (NC_007977.1) and the mitochondrial genome of $H$. annuus (NC_023337.1) from the NCBI database. A few important properties of these primers are provided in Table 1. The PCR protocol was conducted in $25 \mu \mathrm{L}$ of mixture according to manufacturer's instructions
(Eurogen, Moscow, Russia). The PCR cycles with the following specification: initial denaturation for $5 \mathrm{~min}$ at $95^{\circ} \mathrm{C}, 30$ cycles of $15 \mathrm{~s}$ at $95^{\circ} \mathrm{C}$ (denaturation), $25 \mathrm{~s}$ at $58^{\circ} \mathrm{C}, 1 \mathrm{~min} 72^{\circ} \mathrm{C}$ and a final elongation for $10 \mathrm{~min}$ at $72^{\circ} \mathrm{C}$. Amplification was performed in a thermocycler C1000 (Bio-Rad, California, USA).

\section{Data Analysis}

The level of cpSSR and mtSSR loci polymorphism was assessed by the Polymorphism Information Content (PIC) index, which was calculated as follows: PIC $=1$ $\sum$ pi2, where pi is frequency of $\mathrm{i}$-th allele detected in the analyzed sampling (Nei, 1973).

A binary matrix was constructed by converting the data of allele sizes into " 1 ", (present) or " 0 ", (absence). UPGMA cluster analysis was completed with the treecon $1.3 \mathrm{~b}$ software.

Table 1: Primers used in the SSR analysis

\begin{tabular}{|c|c|c|c|c|c|c|}
\hline Genome & № & Locus name & Sequence of flanking primers $5^{\prime}-3^{\prime}$ & $\begin{array}{l}\text { Number } \\
\text { of alleles }\end{array}$ & $\begin{array}{l}\text { Size of } \\
\text { amplifications } \\
\text { fragments, bp }\end{array}$ & PIC \\
\hline \multirow[t]{17}{*}{ Chloroplast } & \multirow[t]{2}{*}{1} & \multirow[t]{2}{*}{ clpP, intron } & F: TTCAGCAATCCCAAAGTGGC & \multirow[t]{2}{*}{8} & \multirow[t]{2}{*}{$120-139$} & \multirow[t]{2}{*}{0,959} \\
\hline & & & R: AGTCCAGTTCAGCGTCACAA & & & \\
\hline & \multirow[t]{2}{*}{2} & \multirow[t]{2}{*}{$a t p B-r b c L$} & F: GACGGCTCATCGGGATAGATG & \multirow[t]{2}{*}{6} & \multirow[t]{2}{*}{$149-155$} & \multirow[t]{2}{*}{0,977} \\
\hline & & & R: ATTTTACGGATTCCTTTCCTATCCT & & & \\
\hline & \multirow[t]{2}{*}{3} & \multirow[t]{2}{*}{ clpP, intron } & F: TGAGGGGAAGATACAAAGAAAGAT & \multirow[t]{2}{*}{3} & \multirow[t]{2}{*}{$186-188$} & \multirow[t]{2}{*}{0,937} \\
\hline & & & R: TCTGAAAGGAAGGGTGGTAAGT & & & \\
\hline & \multirow[t]{2}{*}{4} & \multirow[t]{2}{*}{$\operatorname{trn} R-\operatorname{trn} G$} & F: CGCTTTCATTGTGATTTTTGGGT & \multirow[t]{2}{*}{7} & \multirow[t]{2}{*}{$223-247$} & \multirow[t]{2}{*}{0,979} \\
\hline & & & R: CCTTCCAAGCTAACGATGCG & & & \\
\hline & \multirow[t]{2}{*}{5} & \multirow[t]{2}{*}{$\operatorname{trn} M-\operatorname{atp} E$} & F: GGCGGGAGTCATTGGTTCAA & \multirow[t]{2}{*}{10} & \multirow[t]{2}{*}{$276-291$} & \multirow[t]{2}{*}{0,989} \\
\hline & & & R: GCTAGGACACGAGTAGAGGC & & & \\
\hline & 6 & $p s b K-p s b I$ & F: TGTCGGTATGAAAGTGATTTGTGG & 5 & $302-306$ & 0,972 \\
\hline & 7 & $p s b C-t r n S$ & F: CGTCCGGTCAAAACCAATCC & 12 & $322-336$ & 0.995 \\
\hline & & & R: GTACATGGAGTCGGGGGAGA & & & \\
\hline & 8 & clpP, intron & F: CGCCTTTTGACGCATACGGT & 13 & $350-378$ & 0,994 \\
\hline & & & R: TGTGCAAATCAAAATCGGGCG & & & \\
\hline & 9 & rpoCl, intron & F: AGCCGGATGAAAGGAAACTT & 5 & $386-390$ & 0,977 \\
\hline & & & R: TGCTTAGCCAATTCCATGCG & & & \\
\hline Mitochondrial & 10 & $\operatorname{trn} E-\operatorname{cox} I$ & F: CGAACGAGATAAGGTTGTCAAATG & 3 & $128-130$ & 0,883 \\
\hline & & & R: GGAAGAATGGATCCGAACGAA & & & \\
\hline & 11 & $\operatorname{trn} S-c o b$ & F: GGACGCGAGAACCTAAGAAA & 10 & $158-169$ & 0,991 \\
\hline & & & R: GAGCGCTCCTGCACTATAC & & & \\
\hline & 12 & $r p l 16-m a t R$ & F: GCTCATCACCAGGTCCAATAG & 6 & $176-181$ & 0,950 \\
\hline & & & R: GTTCGGGACGGCTGTATTT & & & \\
\hline & 13 & atpl-ccmFn & F: GCAATACGGAGAGAGGTAGAAAG & 4 & $277-283$ & 0,912 \\
\hline & & & R: CCATGCCTTCTAATCGGCTAAT & & & \\
\hline & 14 & atpl $-c c m F n$ & F: CTCGTAGCTCCCGTTTGATAC & 5 & $334-338$ & 0,964 \\
\hline & & & R: TGTCCTTGATGACCAACCATAA & & & \\
\hline & 15 & $\operatorname{trn} S-c o b$ & $\begin{array}{l}\text { F: CTTGTTCCGTGCTATTGAGAGA } \\
\text { R: AATCGTAGGTCCCCTCGTC }\end{array}$ & 8 & $373-384$ & 0,976 \\
\hline & 16 & atp6-trnK & F: GCTCGGCTAAATAGGCTCAAT & 4 & 394-397 & 0,958 \\
\hline & & & R: CСССТTCTCTGCTCCTTTCC & & & \\
\hline & 17 & $r p l 5-\operatorname{trn} D$ & F: AGTGGGAAGTAATGAGGCTAGT & 4 & $432-435$ & 0,964 \\
\hline & & & R: CCCATGACTTTCCGGACCAA & & & \\
\hline & 18 & $\operatorname{trn} D-\operatorname{trn} K$ & F: GCTGTACACCTGGGATTGTAG & 4 & $460-464$ & 0,921 \\
\hline & & & R: CGCTGACCGAATTCTGCTTC & & & \\
\hline
\end{tabular}




\section{Results and Discussion}

In the present work, the polymorphism of 18 microsatellite loci of the chloroplast and mitochondrial genomes was investigated. The number of detectable alleles with use of the primers system ranged from 3 to 13 and averaged 6,5 for investigated samples. The greatest polymorphism was shown for 5, 7, 8, 11 primer pairs and was represented by $10,12,13,10$ allelic variants, respectively. Sizes of amplified fragments ranged from 120 to $465 \mathrm{bp}$. Locuses is characterized by high heterogeneity, which is confirmed by the high values of PIC which was from 0,883 to 0,995 Table 1 . Most lines have their own unique patterns that different from each other.
Based on the obtained data was constructed UPGMA-dendrogram showing the genetic diversity of chloroplast, mitochondrial genomes and citoplasmons in generally of sunflowers.

The dendrogram constructed for the chloroplast genomes includes three major clusters Fig. 1. The first cluster includes cultivar lines of sunflower. The second cluster is represented by annual sunflower species: H. argophyllus, $H$. bolanderi, $H$. debilis, $H$. neglectus, $H$. praecox, $H$. petiolaris and 15 different numbers of introductions of $H$. annuus. The third cluster consists of perennial sunflower species: $H$. decapetalus, $H$. divaricatus, $H$. grosseserratus, $H$. hirsutus, $H$. microcephalus, $H$. occidentalis, $H$. rigidus, $H$. salicifolius, H. strumosus, H. tuberosus.

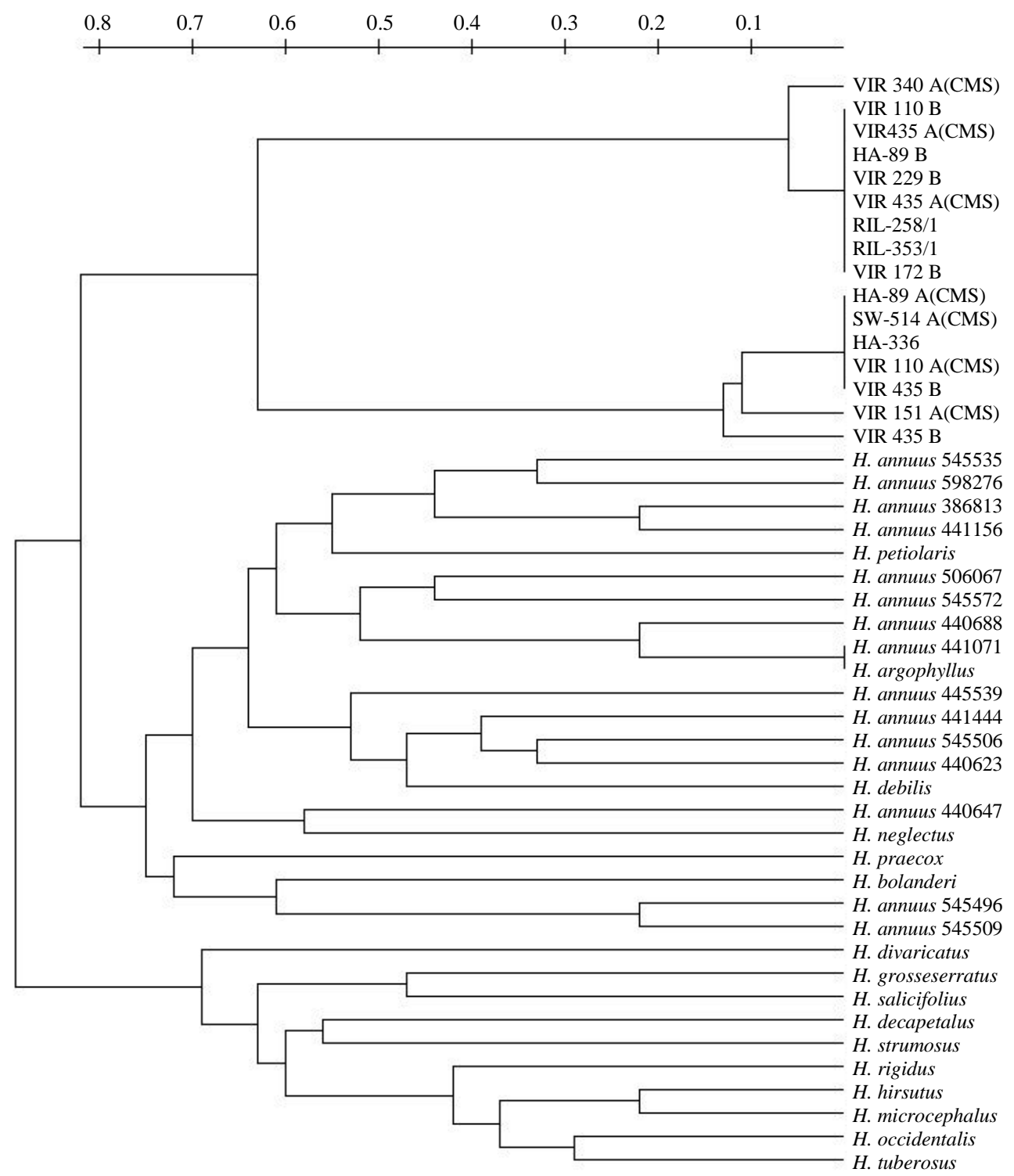

Fig. 1: The dendrogram of genetic diversity of sunflower, based on the results of SSR-analysis of cpDNA 


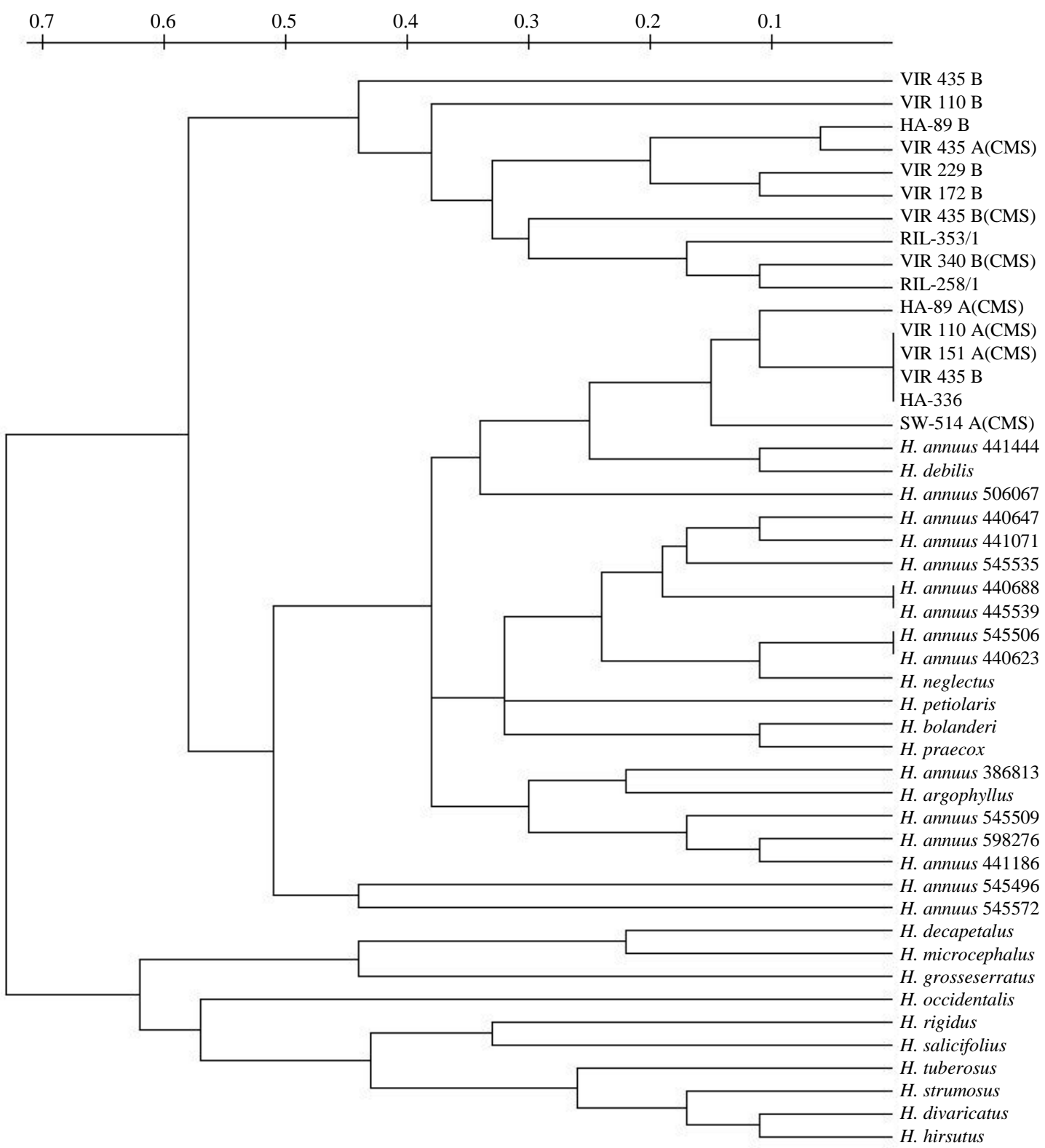

Fig. 2: The dendrogram of genetic diversity of sunflower, based on the results of SSR-analysis of mtDNA

The dendrogram constructed for the mitochondrial genomes includes three major clusters too Fig. 2. However, the cluster of wild annual forms sunflower includes cultivar lines such as HA-89 A (CMS), VIR 110 A (CMS), VIR 151 A (CMS), VIR 435 B, HA-336, SW514 A (CMS).

The complete dendrogram constructed for the chloroplast and mitochondrial genomes includes three main clusters too but shows better detalization than individual ones Fig. 3.

Differentiation into annual and perennial species is probably due to the accumulation of mutations in the genome over time. These mutations are localized in intergenic regions and do not receive the pressure of natural selection (Singh et al., 2015). It is known that the selection process leads to the appearance of many homozygotes and, as a result, to a reduction in genetic diversity (Markin et al., 2015). This explains the separation of cultural lines from annual wild species. The investigated markers are suitable for certification of a linear material and searching of genetic raw materials for selection.

Molecular markers can be used for genetic variation analysis if it has high polymorphism, codominance and specific characteristics and wide distribution (Aristya et al., 2019). 


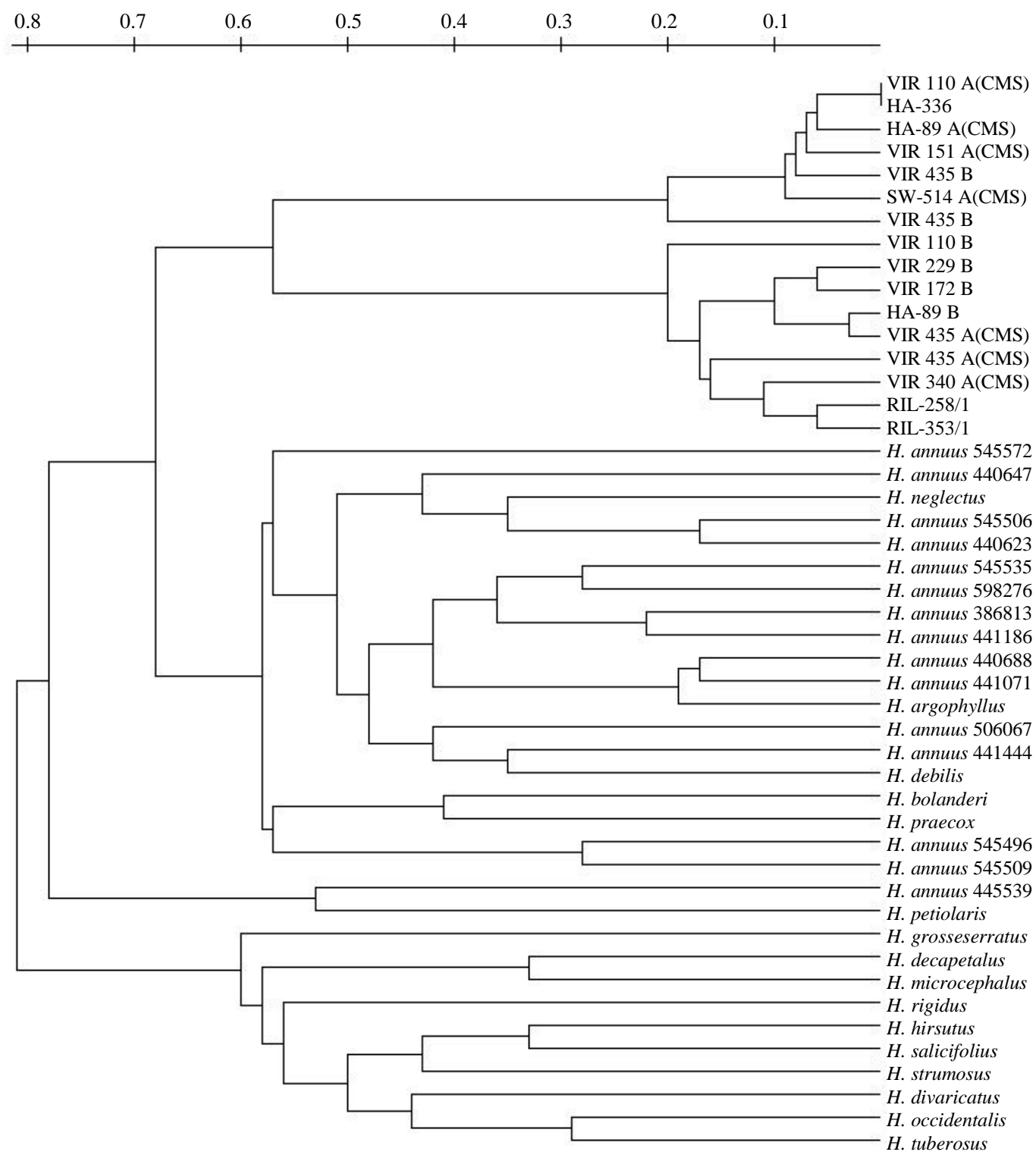

Fig. 3: The dendrogram of genetic diversity of sunflower, based on the results of SSR-analysis of cpDNA and mtDNA

\section{Conclusion}

The 18 polymorphic SSR markers developed here proved useful in the evaluation of the genetic diversity of sunflowers. All 18 SSR markers showed high polymorphic information content index for annual and perennial species. Based on the obtained data was constructed UPGMA-dendrogram showing the genetic diversity of chloroplast and mitochondrial genomes of sunflowers. This set of novel polymorphic SSR markers can be useful for breeders and molecular biologists for the genetic diversity analysis, lines identification and improve breeding.

\section{Acknowledgement}

This research was supported by a project of the Ministry Education and Science of Russia, no. 6.929.2017/4.6.

\section{Funding Information}

The funders of this manuscript were the Ministry Education and Science of Russia, no. 6.929.2017/4.6.

\section{Author's Contributions}

Vladimir Arturovich Khachumov: Wrote the first draft of the manuscript, designed experiments participated 
in the laboratory study, participated in the collected and data analysis, read and approved the final manuscript.

Alexander Vyacheslavovich Usatov: Designed experiments, read and approved the final manuscript.

Kirill Vitalievich Azarin: Designed experiments, data analysis. Author read and approved the final manuscript.

Nikolay Victorovich Markin: Participated in the laboratory study, data analysis, read and approved the final manuscript.

Vera Alekseevna Gavrilova: Collected and analyzed data. Author read and approved the final manuscript.

Oleg Fedorovich Gorbachenko and Fedor Ivanovich Gorbachenko: Designed experiments, read and approved the final manuscript.

\section{Ethics}

The authors state that this article conforms to the ethical standards specified by the American Journal of Biochemistry and Biotechnology.

\section{References}

Aristya, G.R., R. Kasiamdari, M.F. Arif, F. Amalia and R.D. Pawestri, 2019. Comparison of molecular markers ISSR, SSR and RFLP to study the genetic variation of strawberry cultivars. Am. J. Agric. Biol. Sci., 14: 61-68.

DOI: 10.3844/ajabssp.2019.61.68

Bohra, A., R. Jha, G. Pandey, P.G. Patil and R.K. Saxena et al., 2017. New hypervariable SSR markers for diversity analysis, hybrid purity testing and trait mapping in Pigeonpea [Cajanus cajan (L.) Millspaugh]. Frontiers Plant Sci., 8: 1-15. DOI: $10.3389 /$ fpls.2017.00377

Boom, R.C.J.A., C.J. Sol, M.M. Salimans, C.L. Jansen and P.M. Wertheim-van Dillen et al., 1990. Rapid and simple method for purification of nucleic acids. J. Clin. Microbiol., 28: 495-503.

DOI: 10.1128/JCM.28.3.495-503.1990

Kaur, K., S.K. Dhillon, B.S. Gill and G. Kaur, 2019. Association of SSR based genetic distances with heterosis in sunflower. J. Environ. Biol., 40: 1102-1108. DOI: $10.22438 / \mathrm{jeb} / 40 / 5 / \mathrm{MRN}-953$

Markin, N.V., A.V. Usatov, M.D. Logacheva, K.V. Azarin and O.F. Gorbachenko et al., 2015. Study of chloroplast DNA polymorphism in the sunflower (Helianthus L.). Russian J. Genet., 51: 745-751. DOI: 10.1134/S1022795415060101

Mashkina, E.V., A.V. Usatov and M.V. Skorina, 2010. Comparative analysis of thermotolerance of sunflower chlorophyll mutants. Russian J. Genet., 46: 178-184. DOI: 10.1134/S1022795410020079
Mornkham, T., P.P. Wangsomnuk, X.C. Mo, F.O. Francisco and L.Z. Gao et al., 2016. Development and characterization of novel EST-SSR markers and their application for genetic diversity analysis of Jerusalem artichoke (Helianthus tuberosus L.). Genet. Mol. Res., 15: 1-16. DOI: 10.4238/gmr15048857

Nei, M., 1973. Analysis of gene diversity in subdivided populations. Proc. National Acad. Sci., 70: 3321-3323. DOI: 10.1073/pnas.70.12.3321

Singh, A.K., P.K. Singh, M. Arya, N.K. Singh and U.S. Singh, 2015. Molecular screening of blast resistance genes in Rice using SSR markers. Plant Pathol. J., 31: 12. DOI: 10.5423/PPJ.OA.06.2014.0054

Sobanski, J., P. Giavalisco, A. Fischer, J.M. Kreiner and D. Walther et al., 2019. Chloroplast competition is controlled by lipid biosynthesis in evening primroses. Proc. National Acad. Sci., 116: 5665-5674. DOI: $10.1073 /$ pnas.1811661116

Song, J.Y., G.A. Lee, M.S. Yoon, K.H. Ma and Y.M. Choi et al., 2018. Analysis of Genetic Diversity and Population Structure of Buckwheat (Fagopyrum esculentum Moench.) Landraces of Korea using SSR Markers. In: Buckwheat Germplasm in the World, Zhou, M., I. Kreft, G. Suvorova, Y. Tang and S.H. Woo (Eds.), Academic Press, ISBN-10: 978-0-12-811006-5 pp: 315-331.

Usatov, A.V., A.I. Klimenko, K.V. Azarin, O.F. Gorbachenko and N.V. Markin et al., 2014. The relationship between heterosis and genetic distances based on SSR markers in Helianthus annuus. Am. J. Agric. Biol. Sci., 9: 270-276. DOI: 10.3844/ajabssp.2014.270.276

Usatov, A.V., P.I. Kostylev, K.V. Azarin, N.V. Markin and M.S. Makarenko et al., 2016. Introgression of the rice blast resistance genes $\mathrm{Pi} 1, \mathrm{Pi} 2$ and $\mathrm{Pi} 33$ into Russian rice varieties by marker-assisted selection. Indian J. Genet. Plant Breed., 76: 18-23. DOI: 10.5958/0975-6906.2016.00003.1

Wills, D.M., M.L. Hester, A. Liu and J.M. Burke, 2005. Chloroplast SSR polymorphisms in the Compositae and the mode of organellar inheritance in Helianthus annuus. Theoretical Applied Genet., 110: 941-947. DOI: 10.1007/s00122-004-1914-3

Zong, J.W., T.T. Zhao, Q.H. Ma, L.S. Liang and G.X. Wang, 2015. Assessment of genetic diversity and population genetic structure of Corylus mandshurica in China using SSR markers. Plos One, 10: 1-12. DOI: 10.1371/journal.pone.0137528 